\title{
How Low Can You Go? Exploring the Lower Limit of Crystal Size on a Home X-ray Source
}

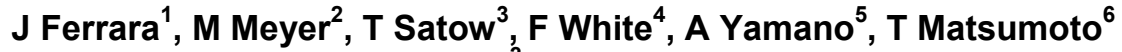 \\ ${ }^{1}$ Rigaku Americas Corp, The Woodlands, TX, ${ }^{2}$ Rigaku Polska Sp. z 0.o., Wroclaw, Poland, ${ }^{3}$ Rigaku \\ Corporation, Tokyo, Japan, ${ }^{4}$ Rigaku Europe SE, Neu-Isenburg, Germany, ${ }^{5}$ Application \\ Laboratories, Rigaku Corporation, ${ }^{6}$ Rigaku Corp., Akishima, Japan \\ joseph.ferrara@rigaku.com
}

There is a misconception in the literature (Gruene, [i]et. al.[/i], 2018) that one needs crystals as large as $50 \mu \mathrm{m}$ on a side to perform single X-ray diffraction studies. It has also been suggested that MicroED measurements are needed to probe smaller samples. In this presentation, we will demonstrate that this is simply not true. Furthermore, we will show the lower limit of what is possible with a home X-ray source is somewhere just above the upper range of what is accessible to MicroED, that is, about 1-3 $\mu \mathrm{m}$.

We will also compare some X-ray and ED structural quality and make some suggestions regarding classification of different types of structures based on quality of the results.

Gruene, T.; Wennmacher, J. T. C.; Zaubitzer, C.; Holstein, J. J.; Heidler, J.; Fecteau-Lefebvre, A.; De Carlo, S.; Müller, E.; Goldie, K. N.; Regeni, I.; Li, T.; Santiso-Quinones, G.; Steinfeld, G.; Handschin, S.; van Genderen, E.; van Bokhoven, J. A.; Clever, G. H.; Pantelic, R. Rapid Structure Determination of Microcrystalline Molecular Compounds Using Electron Diffraction. [i]Angew. Chem. Int. Ed.[/i] (2018). [b]57[/b], 16313-16317;.

Acta Cryst. (2020). A76, a74 